REVIEW

\title{
Management of portal hypertension
}

\author{
D N Samonakis, C K Triantos, U Thalheimer, D W Patch, A K Burroughs
}

Postgrad Med J 2004;80:634-641. doi: 10.1136/pgmj.2004.020446

Treatment of portal hypertension is evolving based on randomised controlled trials. In acute variceal bleeding, prophylactic antibiotics are mandatory, reducing mortality as well as preventing infections. Terlipressin or somatostatin combined with endoscopic ligation or sclerotherapy is the best strategy for control of bleeding but there is no added effect of vasoactive drugs on mortality. Non-selective $\beta$-blockers are the first choice therapy for both secondary and primary prevention; if contraindications or intolerance to $\beta$-blockers are present then band ligation should be used. Novel therapies target the increased intrahepatic resistance caused by microcirculatory intrahepatic deficiency of nitric oxide and contraction of activated intrahepatic stellate cells.

See end of article for authors' affiliations

....................

Correspondence to: Professor Andrew K Burroughs, Liver Transplant and Hepatobiliary Medicine Unit, Royal Free Hospital, Pond Street, London NW3 2QG, UK; andrew. burroughs@royalfree.nhs. uk

Submitted

12 February 2004

Accepted 22 April 2004
$\mathrm{P}$ ortal hypertension is the major complication of cirrhosis and is responsible for complications such as massive gastrointestinal bleeding (oesophageal or gastric varices), ascites, pathy. Portal hypertension is defined by a raised portal pressure above the normal values of 1-5 mm Hg; clinically significant portal hypertension is defined above the threshold of $12 \mathrm{~mm}$ $\mathrm{Hg}$ due to the potential development of portal hypertensive bleeding, ${ }^{1}$ the most serious complication of portal hypertension, as it is associated with high morbidity and mortality rate. ${ }^{2}$

Prospective studies have shown that more than $90 \%$ of cirrhotic patients will develop oesophageal varices sometime in their lifetime and of these $30 \%$ will bleed, ${ }^{3}{ }^{4}$ and usually once developed, the varices increase from small to large, though regression has been reported with the improvement in liver function and abstinence from alcohol. ${ }^{5}$ The most important predictive factors for the risk of bleeding are severity of liver dysfunction (Child-Pugh classification; see tablel), larger size of varices (increased tension of the variceal wall), and presence of red signs on the varices.

These factors are combined in the North Italian Endoscopic Club Index for the prediction of the first bleeding. It is important to realise that patients with small varices and no red signs and Child-Pugh C score have a risk of $20 \%$ for first bleeding compared with a patient with ChildPugh A score, large varices, and moderate red signs who has a $24 \%$ risk and a Child-Pugh C patient with small varices and moderate red signs who has a risk of $36 \%$, thus underlying the importance of the liver function impairment. hepatorenal syndrome, and hepatic encephalo-
However $30 \%$ of patients will first bleed without these risk factors. ${ }^{4}$ Increased variceal pressure has been shown to add to this model. ${ }^{7}$ Moreover, $5 \%-50 \%$ of cirrhotic patients (depending on the severity of the underlying liver dysfunction) with acute variceal bleeding will die often during the first days after the initial episode. ${ }^{2}$ Predictive factors of failure to control bleeding are active bleeding at endoscopy spurting or oozing (usually at the oesophagogastric junction), severity of liver disease, ${ }^{8}$ raised portal pressure hepatic venous pressure gradient (HVPG) $\geqslant 20 \mathrm{~mm} \mathrm{Hg}$ measured early after admission, ${ }^{9}$ and presence of bacterial infection. ${ }^{10}$ There is a high rate of early rebleeding in the first weeks after bleeding, which without specific treatment occurs in up to $50 \%$ within six weeks of admission. ${ }^{11}$ Although mortality from acute variceal bleeding has been decreasing, ${ }^{12}{ }^{13}$ it still remains high $(5 \%-35 \%)$ depending on the severity of liver disease and the age of the patient.

There is a well documented association of variceal haemorrhage and bacterial infections $^{10} 1415$ that may represent a causal relationship. A hypothesis suggests infection is the triggering factor for the variceal bleeding. ${ }^{16}$ Two crucial steps for the onset of haemorrhage, which are related to the release of endotoxin into the systemic circulation, are vasoconstrictor induced contraction of stellate cells and worsening of haemostasis. ${ }^{16}$

Portal hypertensive gastropathy (PHG) is a term used to describe the endoscopic appearance of the gastric mucosa, with characteristic mosaiclike pattern with or without cherry red spots, and is a common finding in patients with portal hypertension. Histologically there are dilated capillaries and venules in the mucosa and submucosa without erosion, inflammation, or fibrinous thrombi. ${ }^{17}$ The pathogenesis is not clearly defined and its prevalence parallels the severity of portal hypertension. It can progress from mild to severe and vice versa or even disappear completely, but bleeding is relatively uncommon and rarely severe. ${ }^{18}$ The same vasoactive agents used for variceal bleeding are used for PHG bleeding. ${ }^{19}$ In an uncontrolled study, somatostatin and octreotide has been shown effective in the context of acute bleeding from $\mathrm{PHG}^{20}$ Endoscopic treatment does not have a role, whereas transjugular intrahepatic portosystemic shunts (TIPSs) and shunt surgery should be only

\footnotetext{
Abbreviations: $\mathrm{Cl}$, confidence interval; $\mathrm{HSC}$, hepatic stellate cell; HVPG, hepatic venous pressure gradient; OR, odds ratio; PHG, portal hypertensive gastropathy; RR, relative risk; TIPS, transjugular intrahepatic portosystemic shunt
} 
Table 1 Child-Pugh grading of the severity of liver disease

\begin{tabular}{llll}
\hline Variable & Score 1 & Score 2 & Score 3 \\
\hline Ascites & Absent & Mild & Moderate/severe \\
Encephalopathy & Absent & Stage I/II & Stage III/IV \\
Albumin (g/l) & $>35$ & $28-35$ & $<28$ \\
Bilirubin ( $\mu \mathrm{mol} / \mathrm{I})$ & $<34$ & $34-51$ & $>51$ \\
$\quad$ For PBC & $<68$ & $68-170$ & $>170$ \\
$\begin{array}{l}\text { Prothrombin time (sec } \\
\text { prolonged) }\end{array}$ & 4 & $4-6$ & $>6$ \\
$\quad$ Comparable INR & $<1.7$ & $1.7-2.3$ & $>2.3$ \\
\hline
\end{tabular}

Child-Pugh A: 5-6 points; B: 7-9 points; C: 10-15 points.

INR, international normalised ratio; $\mathrm{PBC}$, primary biliary cirrhosis.

used as a last resort and in patients where the benefit outweighs the risk. Only non-selective $\beta$-blockers can prevent first and secondary bleeding from PHG. ${ }^{21}$

\section{ACUTE VARICEAL BLEEDING} (1) General management

The cirrhotic patient is a complicated one who requires intensive nursing care and careful medical assessment. In particular, effective resuscitation, accurate diagnosis, and early treatment can reduce mortality. ${ }^{22}$ The initial priority is the protection of airway to prevent aspiration, with intubation to be considered in patients with impaired level of consciousness and severe uncontrolled bleeding particularly for endoscopy. A normal central venous pressure should be maintained (avoidance of prolonged hypovolaemia is very important to avoid the complications of renal failure and infection), but over transfusion (according to data from animal models) should be avoided because of the risk for rebound increase in portal pressure, with subsequently increased risk of poor control of bleeding. ${ }^{23}$

Most importantly, prophylaxis of bacterial infection with oral quinolones or intravenous broad spectrum antibiotics has been shown not only to reduce infectious complications (relative risk (RR) 0.39 ; 95\% confidence interval (CI) 0.32 to 0.48 ) but also to reduce mortality (RR $0.39 ; 95 \%$ CI 0.32 to $0.48) .{ }^{24}$ The effect on mortality is greater than that seen with specific vasoactive drugs versus placebo. Maintenance of renal function is of prime importance and therefore terlipressin may have an added role, as with albumin it can reverse hepatorenal syndrome. ${ }^{25}$

\section{(2) Specific therapy}

The data on drugs favour the use of terlipressin ( 2 mg every four hours for the initial 24 hours and $1 \mathrm{mg}$ four hourly for the next 24 hours; some units prolong its use to five days), as it is the only drug to have shown a reduction in mortality in acute variceal bleeding. ${ }^{26}$ Interestingly, early (before hospital admission) administration of terlipressin-plus glycerine trinitrate-improved the control of bleeding and reduced mortality. ${ }^{27}{ }^{28}$ A Cochrane review on somatostatin and its analogues has only shown a reduction of one unit in terms of transfusion requirements. ${ }^{29}$ Recently, recombinant activated factor VII is related with transient improvement of haemostasis in the setting of acute variceal bleeding; further testing is needed. ${ }^{30} 31$

Endoscopic therapy has been considered the mainstay of specific treatment for acute variceal bleeding ${ }^{32}$ (provided that such facilities are available), with some authors emphasising the need for expert and rapid control of haemorrhage. ${ }^{33}$

Although randomised trials of sclerotherapy ${ }^{32}$ versus banding ligation have shown that ligation is more effective (pooled odds ratio (OR) 0.51 ; $95 \%$ CI 0.34 to 0.79 ) in controlling bleeding, ${ }^{34}$ there is no statistical difference in survival. As placement of the banding device requires extubation after the diagnostic endoscopy and then reintubation, this probably increases the risks of endoscopy, but this has not been assessed formally. The choice of technique should be left up to the experience of the operator, and the particular circumstances found during diagnostic endoscopy.

A cumulative meta-analysis of trials of sclerotherapy versus vasoactive drugs clearly shows the consistent effect over time of the superiority of sclerotherapy for control of bleeding (OR 1.384; 95\% CI 0.977 to 1.962 ) and also similar pattern for hospital or 42 day mortality (pooled OR 1.354; 1.032 to 1.777 ) but the effect is weak. A recent metaanalysis, ${ }^{35}$ which excluded one randomised trial $^{36}$ and included another that was difficult to obtain the correct numbers for $^{37}$ (and also did not confine the evaluation of efficacy to seven days but to six weeks), suggested drugs were equivalent. However, this interpretation is open to question as assessment should be only during the emergency period. In addition the evidence for efficacy of drugs on their own is very weak except for terlipressin. Finally, trials of sclerotherapy versus standard therapy (drugs \pm balloon) showed the superiority of sclerotherapy. ${ }^{27}$

To date the best evidence for efficacy in treating acute variceal bleeding is drugs combined with endoscopic treatment. Randomised trials have shown the greatest effect on control of bleeding (for initial five day control) but strangely no effect on mortality. ${ }^{38}$ This apparent paradox may be explained by the great variability in the efficacy rates of sclerotherapy used on its own in this group of studies, ${ }^{27}$ and makes the interpretation of meta-analysis difficult.

\section{(3) Rescue therapy}

There is no accepted definition regarding failure of drug and endoscopic therapy for acute variceal bleeding, but most units will only use two sessions of emergency endoscopic therapy. ${ }^{39}$ The rescue therapy of choice today is TIPS and if this is not available, staple transection of the oesophagus. TIPS is very effective in stopping bleeding in over $90 \%$ of the patients. ${ }^{40}$ Sources of continued bleeding or early rebleeding are often oesophageal ulcers caused by previous endoscopic therapy which is why endoscopic therapy should be limited in the acute setting. There are no randomised trials comparing TIPS with surgical treatments in uncontrolled variceal haemorrhage. It has been shown in uncontrolled studies that TIPS is highly effective in stopping variceal haemorrhage ${ }^{41-45}$ but on the other hand TIPS in uncontrolled variceal bleeding still has a high mortality.$^{46}$ Prognosis is poor if patients have developed sepsis, required inotropic support and ventilation (often due to aspiration), and if they have deteriorating liver and renal function, ${ }^{47}$ which still is a scenario when a TIPS could be placed. The technical expertise now exists to place TIPS in virtually any patient, even when portal vein thrombosis is present. Thus issues of the utility of treatment arise. ${ }^{47}$ Established renal failure in a cirrhotic who has had uncontrollable bleeding is in our unit a contraindication to TIPS placement. 
When TIPS is not available, alternative options are injections of tissue adhesives (Histoacryl, Bucrylate) or fibrin glue, or endoscopic detachable snare (Endoloops). There are no controlled data for these therapies. If there is a skilled operator it is certainly worth attempting in the absence of TIPS, particularly when the patient is a poor candidate for surgery. ${ }^{27}$

\section{GASTRIC VARICES}

Gastric varices can be found alone or in combination with oesophageal varices and the incidence of bleeding in most series is less than $10 \% .{ }^{44}$ Patients with gastric variceal haemorrhage bleed more profusely, require more transfusions, have a higher risk of rebleeding, and have a higher mortality compared with those who bleed from oesophageal varices. ${ }^{48}$ The optimal treatment of gastric varices is not known. Sclerotherapy and banding are not useful. Bucrylate has shown better results than sclerosants in a study with 27 patients bleeding from oesophagogastric varices, ${ }^{49}$ and in another study was reported superior to ethanolamine, although the survival advantage of Bucrylate seemed partially related to increased early rebleeding rates in the ethanolamine group. ${ }^{50}$ In a recent randomised trial of 37 patients cyanoacrylate was more effective than alcohol injection in achieving faster obliteration of gastric varices, and appeared more useful in controlling acute gastric variceal bleeding, reducing the need for rescue surgery while mortality was similar in the two groups.$^{51}$ Nevertheless, reports of cerebral and pulmonary embolism with tissue adhesives constitute a major drawback coupled with the expertise in their use. The protocol for tissue adhesives must be well worked out.

Bovine thrombin has been used as intravariceal injection and in a study with 11 cases initial haemostasis was achieved in all patients and after a median follow up of nine months; only one patient rebled from gastric varices. The substitution of bovine with recombinant thrombin is expected to overcome the problem for possible transmission of the agent responsible for bovine spongiform encephalopathy. ${ }^{52}$ The combination of fibrinogen with thrombin was evaluated in a small study giving very good results in controlling gastric variceal bleeding. ${ }^{53}$

Unfortunately in all these studies there are considerable rebleeding rates; hence for patients with rebleeding or uncontrolled bleeding, there is the option of TIPS or surgery. TIPSs have been shown to be as effective for gastric bleeding as for oesophageal variceal bleeding, having high success rates for initial haemostasis and acceptable rebleeding rates. ${ }^{44} 5455$

\section{PREVENTION OF RECURRENT VARICEAL BLEEDING (SECONDARY PROPHYLAXIS)}

As patients surviving the first episode of variceal bleeding are at very high risk of recurrent bleeding $(70 \%$ or more at one year) and death $(30 \%-50 \%)$, expectant management is not an

Box 1: Primary prevention of portal

hypertensive bleeding

- In cirrhotics screening for varices currently should be performed by endoscopy.

- In the presence of moderate/large varices or small varices with severe liver dysfunction, non-selective $\beta$-blockers are the therapy of first choice.

- Endoscopic banding should be reserved for those intolerant or with contraindications to $\beta$-blockers. option. ${ }^{56}$ Patients with poor liver function or with other complications of portal hypertension should also be considered for liver transplantation.

The therapy of choice is non-selective $\beta$-blockers, with or without nitrates. A meta-analysis of four trials with 471 patients ${ }^{57-60}$ comparing drugs with elective long term banding ligation has shown equivalence both for rebleeding (pooled OR $0.966 ; 95 \%$ CI 0.66 to 1.41 ) and mortality (pooled OR $0.72 ; 95 \%$ CI 0.47 to 1.1 ), although in the latter end point there was a trend in favour of drug combination. ${ }^{27}$ If there is intolerance or contraindications to $\beta$-blockers, then banding should be used. Band ligation is superior to long term sclerotherapy as it is associated with significantly lower rebleeding rates as well as complications. ${ }^{27}$ One randomised trial has compared Histoacryl obliteration with propranolol in 41 patients, with no difference in rebleeding rates or survival, but with more complications with the adhesive injection. ${ }^{61}$ There is an unanswered question as to whether combination of endoscopic therapy and $\beta$-blockers is more effective than endoscopic therapy alone. There are few data on ligation and drugs, but considerable data on sclerotherapy combined with drugs. These show greater efficacy with combined therapy, but the results are very heterogeneous with meta-analysis so that it is difficult to draw a proper conclusion. It is unlikely that combination of drugs is more efficacious. Two randomised studies came to opposite conclusions about the efficacy of combined drug therapy versus $\beta$-blockers alone. ${ }^{62}{ }^{63}$

There are 13 randomised trials comparing TIPS with endoscopic therapy (with or without the addition of propranolol), for the prevention of variceal rebleeding, with 948 patients and a median range of follow up between 10 and 32 months. ${ }^{64}$ Rebleeding was less common in patients randomised to TIPS, but there was a consistent but non-significant survival difference in favour of endoscopic therapy. Moreover, hepatic encephalopathy was statistically more common in patients randomised to TIPS. In a more recent study, Escorsell et al compared TIPS to propranolol and isosorbite mononitrate in 91 patients with cirrhosis and Child-Pugh $>7$. Medical treatment was found less effective than TIPS in preventing rebleeding. However, it caused less encephalopathy, but similar survival with more frequent improvement in Child-Pugh class and with lower costs than TIPS. The authors suggest that TIPS should not be used as first line treatment but only as rescue for failures of medical/ endoscopic treatments. ${ }^{65}$ Covered stents are now available. The initial results give better patency rates and survival, but given that worse encephalopathy and portal diversion will occur, the survival benefit may not be borne out. ${ }^{66}$ The old portocaval and distal splenorenal shunt studies showed no benefit in survival compared to no therapy or sclerotherapy respectively for the prevention of variceal rebleednig. ${ }^{27}$

In the era of TIPS there is still a place for surgical shunts in well compensated cirrhotic patients who have troublesome bleeding and who have either failed with endoscopic or drug treatment, or have bled from gastric varices despite other therapies, or have recurrent symptomatic TIPS stenosis, or live far from suitable medical services. Surgical shunts result in at most a $14 \%$ rebleeding rate and survival of $86 \%$, but may cause encephalopathy in $20 \%$ of patients. Small diameter portocaval $\mathrm{H}$ graft or distal splenorenal shunts are probably the favoured surgical option, because the portal vein is still available should liver transplant be required. ${ }^{67} 68$

The recent years HVPG has gained a central role as a useful tool to measure portal pressure indirectly. A reduction of at least $20 \%$ from the baseline HVPG and absolute reduction below $12 \mathrm{~mm} \mathrm{Hg}$ have been suggested as therapeutic targets in portal hypertension. ${ }^{60}{ }^{69}{ }^{70}$ However, a detailed evaluation of current evidence ${ }^{71}$ has suggested this is insufficient to support universal monitoring of targeted reduction of HVPG 
Box 2: Management of acute variceal bleeding

- Transfusion.

- Airway.

- Kidneys

- Electrolytes.

- Coagulation.

- Alcohol withdrawal.

- Resuscitation.

- Encephalopathy.

- Infection.

- Nutrition.

- Oxygen.

- Gastric.

- Varices

(Adapted from Burroughs. ${ }^{119}$ )

- Combined endoscopic therapy and vasoactive drugs is the strategy of choice in acute variceal bleeding.

- Currently the drug of choice is terlipressin, with the alternative of somatostatin, preferably for 5 days.

- TIPS has a role as salvage treatment for uncontrolled bleeding.

in routine clinical practice. This needs to be resolved by a randomised study designed to assess both clinical applicability and validity.

\section{RANDOMISED CONTROLLED TRIALS OF PRIMARY PREVENTION}

Primary prophylaxis refers to patients who have never had previous variceal bleeding. Current recommendations ${ }^{72}$ pertain only to cirrhotics with large varices (defined as those larger than $5 \mathrm{~mm}$ in diameter) as randomised trials have been performed mainly with these patients. However numerically in a consecutive cohort of cirrhotics, more patients with small varices will bleed, than those with large ones. ${ }^{4}$ The ideal prophylactic treatment should be reasonably effective, easy to administer, and have few side effects. This fits perfectly with non-selective $\beta$-adrenergic blockers which meet all these criteria. Meta-analysis demonstrates that propranolol or nadolol reduce bleeding risk from $25 \%$ to $15 \%$ over a median follow up period of two years and mortality is slightly reduced. ${ }^{73}$ The benefit has been proven for both moderate or large varices, irrespective of the severity of liver dysfunction. ${ }^{74} \beta$-Blockers should be continued life long as when they are withdrawn the risk of variceal haemorrhage appears to return to that of the untreated population. ${ }^{75}$ Patients who discontinue $\beta$-blockers have an increased risk of death compared with an untreated population. Unfortunately, there are patients $(15 \%-20 \%)$ who cannot tolerate treatment with $\beta$-blockers or have relative or absolute contraindications. ${ }^{76}$ There is no clear recommendation for this subset of patients so that alternatives have been tried. The ability of vasodilating agents like isosorbide mononitrate to reduce portal pressure ${ }^{77}$ appeared an attractive alternative treatment to patients intolerant of $\beta$-blockers. However, substitution by nitrates on their own is not recommended as there is increased mortality and an increase in the development of ascites..$^{72} 78$ Combination of $\beta$-blockers with nitrates has shown no advantage in one study ${ }^{79}$ but advantage in another. ${ }^{80} 81$ There is no clinical evidence to support this combination. Non-selective $\beta$-blockers remain the cornerstone of the primary prophylaxis of portal hypertensive bleeding.

There are seven randomised trials comparing endoscopic band ligation with propranolol. In general these studies are characterised by small patient numbers, different doses of $\beta$ blocker, and different study design. They show equivalence between the two therapies: pooled OR for first bleeding 1.61 (95\% CI 0.98 to 2.66) and for mortality 0.93 (95\% CI 0.58 to 1.49). This does not alter current practice of using nonselective $\beta$-blockers as the treatment of choice. ${ }^{82-84}$ However, for patients intolerant to $\beta$-blockers, band ligation can be caused. It is salutary to remember that prophylactic sclerotherapy caused harm and its use was abandoned. ${ }^{27}$ In one recent study reported in abstract form endoscopic band ligation was no better than no treatment and caused some bleeding from ulcers. ${ }^{85}$

\section{SCREENING AND PRE-PRIMARY PROPHYLAXIS}

Despite the progress in the treatment of portal hypertension in cirrhotic patients that has been achieved during the last decades, variceal bleeding still occurs with an attendant morbidity and mortality. Prevention is clearly the most appropriate clinical setting to improve management. Screening for varices in cirrhotics should be part of routine clinical practice and if they are found there is an argument for prophylactic treatment ( $\beta$-blockers if they can be given) to prevent portal hypertensive bleeding.

Varices eventually develop in all cirrhotics ${ }^{3}{ }^{4}$ and their prevalence is higher in decompensated cirrhosis. Large varices have higher propensity than the small ones to bleed but the severity of liver dysfunction, particularly in nonalcoholics who usually encounter worsening liver disease with time, is also a very important risk factor. A case can be made to use cheap, easily administered therapy even when varices are small. There have been efforts towards diagnosing varices without endoscopy using various indirect indices as platelet count, albumin, spleen size, Child-Pugh score, but without a final consensus as whether these can substitute endoscopy. ${ }^{86-89}$ For the time being, endoscopy remains the gold standard for screening cirrhotic patients for varices. It appears reasonable to have an endoscopic follow up of 2-3 years for patients with no varices, adopting the shorter interval for alcoholics, patients with more severe liver disease and for those with endoscopic risk signs. ${ }^{5091}$ With those with small varices, if there is no treatment an interval of $1-2$ years has been recommended.

Pre-primary prophylaxis is the term used for the prevention of the varices. There were experimental models of portal hypertension to suggest possible benefit from treatment with $\beta$-blockers in the prevention of the varices. ${ }^{92}{ }^{93}$ However, a randomised trial by Cales et al evaluated propranolol in the prevention of development of large varices in patients with small varices or without varices. At two years, the propranolol group had significantly more patients with large varices compared with the placebo group. However, the results were judged inconclusive because $41 \%$ of patients in the propranolol group and $31 \%$ in placebo group were lost to follow up. ${ }^{94}$ The effect of another non-selective $\beta$-blocker, timolol, was evaluated with respect to the portal pressure in compensated cirrhotic patients without varices, and the response was compared with that of patients with varices. Timolol was found to be more effective in reducing portal pressure in those without varices, suggesting that non-selective $\beta$ blockers will be more effective in the treatment of portal hypertension when administered at an early stage. ${ }^{95}$ These promising results were tested in a multicentre randomised 
double blind controlled trial of timolol, but no clinical benefit could be demonstrated in cirrhotics without varices. ${ }^{96}$ In cirrhotics with small varices nadolol prevented variceal enlargement in another study.$^{97}$ Clearly the limited data and the inconclusive results mean that pharmacological prevention of varices is not clinically applicable at present.

\section{NOVEL APPROACHES}

Carvedilol is a vasodilating non selective $\beta$-blocker with weak intrinsic anti- $\alpha$-adrenergic activity and calcium channel antagonism..$^{98}$ The most recent evaluation of the published literature reports that carvedilol therapy was associated with mean HVPG reduction of $16 \%-43 \%$ after single or multiple doses. Studies comparing carvedilol with propranolol demonstrated equal or enhanced efficacy in lowering HVPG by carvedilol. A substantial proportion of patients had significant HVPG reduction to below the thresholds associated with levels that prevent variceal bleeding. However, carvedilol was associated with substantial symptomatic hypotension especially in patients with Child-Pugh class B or C. The efficacy and side effects appeared to be dose related, ${ }^{99}$ and thus it seems unlikely that it will replace propranolol for routine use, and it is much more expensive than propranolol.

Most patients with portal hypertension have expanded plasma volume, associated with peripheral vasodilation. The use of antialdosteronic drugs aims at decreasing portal pressure through a decrease in blood volume. The administration of loop diuretics causes acute depletion of plasma volume, with a reduction of portohepatic gradient, but its depletion is promptly followed by an increase in sodium retention. ${ }^{100}$ Chronic administration of spironolactone in patients with cirrhosis without ascites leads to a significant reduction of the HPVG. ${ }^{101}$ Nevens et al demonstrated the efficacy of spironolactone in reducing oesophageal varix pressure, both as single agent and in combination with propranolol in patients not responding to $\beta$-blockers. ${ }^{102}$ Similarly the combination of spironolactone with propranolol resulted in adequate reduction in HVPG, in propranolol resistant portal hypertension in 20 cirrhotic patients. ${ }^{103}$ On the other hand Sugano et al showed that spironolactone as an adjunct to low dose transdermal nitroglycerin did not reduce portal pressure in cirrhotics. ${ }^{104}$ Furthermore a recent preliminary study combining nadolol with spironolactone did not result in less first bleeding than of nadolol alone; however when both bleeding and ascites as end points were considered together, combined therapy found to reduce the incidence of portal hypertensive complications. ${ }^{105}$

It is well known that activation of renin-angiotensinaldosterone system is a frequent finding in cirrhotic patients. Bataller et al showed that angiotensin II both induces

\section{Box 3: Secondary prevention}

- Non-selective $\beta$-blockers are safe and effective, representing the treatment of first choice.

- The combination $\beta$-blockers with isosorbide mononitrate needs further evaluation.

- Contraindications or intolerance to $\beta$-blockers are an indication to use long term banding.

- Baseline and remeasurement of HVPG to assess target reductions of portal pressure needs further evaluation.

- Endoscopic therapy combined with $\beta$-blockers needs further evaluation.

- Selective surgical shunts still have a role in a selected group. contraction of human activated hepatic stellate cells (HSCs) and is mitogenic by acting through ATl receptor subtype. ${ }^{106}$ This shows that activated HSCs are targets for the vasoconstrictor action of angiotensin II in the intrahepatic circulation. ${ }^{106}$ However irbesartan caused in vivo arterial hypotension and renal impairment with modest reduction in portal pressure ${ }^{107}$ and gave no benefit compared with propranolol $^{85}{ }^{108}$ causing systemic hypotension and renal impairment. Although treatment with $25 \mathrm{mg}$ losartan for one week ${ }^{109}$ compared with control patients resulted in a decrease in portal pressure with significant but not symptomatic systemic hypotension (without deterioration of liver and kidney function), another study of $50 \mathrm{mg}$ losartan daily compared with propranolol for six weeks did not reduce HVPG after a variceal bleeding episode. ${ }^{110}$ Moreover losartan caused hypotension and reduced glomerular filtration rate in patients with moderate liver failure. ${ }^{110}$ The most recent study evaluated losartan (25 mg daily) compared with propranolol for a two week period. Losartan was as effective as propranolol in reducing portal pressure in cirrhotics who were not receiving diuretics, and was superior in achieving target level HVPG ${ }^{111}$ However the use of angiotensin converting enzyme inhibitors and angiotensin II antagonists in cirrhosis will precipitate renal failure as they decrease the glomerular filtration rate. ${ }^{112}$ Their safety, let alone their efficacy, needs to be proven whether in combination with $\beta$-blockers or on their own. Angiotensin II inhibitors could be useful drugs for patients with chronic hepatitis without significant portal hypertension, to postpone the development of portal hypertension, as they suppress stellate cell proliferation-that is, have an antifibrotic effect.

The role of HSCs in regulating sinusoidal blood flow is increasingly recognised, especially in the context of liver injury. Endothelin levels are increased in injury and activated HSCs have the ability to respond to endothelins via receptors $A$ and B. Sogni et al reported that bosentan, a mixed antagonist of endothelin A and B receptors, decreased portal pressure in vivo in rats with cirrhosis by reducing hepatocollateral vascular resistance. ${ }^{113}$ In a more recent report, activated rat HSCs were found to have somatostatin receptor subtypes 1, 2, and 3. Somatostatin caused significant partial inhibition of endothelin-1 induced contraction of activated HSCs, mainly by stimulation of somatostatin receptor-1. ${ }^{114}$ On the other hand, endothelin-1 has the capacity to produce both vasoconstrictor and vasodilatory responses. In a recent human study, Vaughan et al found that in patients with end stage cirrhosis, altered endothelin responses may contribute to the generalised dilatation of the circulation that occurs in patients with advanced liver disease. ${ }^{85} 115$

Alterations in endothelial nitric oxide synthetase-derived nitric oxide synthesis in the intrahepatic microcirculation and the splanchnic and systemic vasculature are different and opposite. Liver cirrhosis is associated with endothelial dysfunction and deficiency of endothelial nitric oxide release within the liver. This microcirculatory nitric oxide deficiency results in impaired vasoregulation and enhanced vasoconstriction, which increases vascular tone. Additionally, loss of antithrombotic effects attributed to nitric oxide may also contribute to increased intrahepatic vascular resistance. However, splanchnic and systemic vasculature exhibit marked endothelial over production. In these vascular beds, the increase in endothelial nitric oxide synthetase-derived nitric oxide synthesis mediates arterial vasodilatation and has a crucial role in the development of hyperdynamic circulation in cirrhosis. Hypothetically, restoring the bioavailability of nitric oxide in the liver microcirculation may not only reverse the direct intrahepatic effects of nitric oxide deficiency, but also prevent indirectly the complications that are the consequence of this deficiency and the associated increase in 


\section{Key references for further reading}

- D'Amico G, Pagliaro L, Bosch J. The treatment of portal hypertension: a meta-analytic review. Hepatology 1995;22:332-54.

- Grace ND, Groszmann RJ, Garcia-Tsao G, et al. Portal hypertension and variceal bleeding: an AASLD single topic symposium. Hepatology 1998;28:868-80.

- Goulis J, Patch D, Burroughs AK. Bacterial infection in the pathogenesis of variceal bleeding. Lancet 1999;353:139-42.

- Goulis J, Burroughs AK. Portal hypertensive bleeding. In: McDonald J, Burroughs AK, Feagan B, eds. Evidence based gastroenterology and hepatology. BMJ Books (in press).

- Bosch J, Abraldes JG, Groszmann R. Current management of portal hypertension. J Hepatol 2003;38(suppl 1):S54-S68.

intrahepatic vascular resistance. ${ }^{116} \mathrm{~A}$ nitric oxide releasing derivative of ursodeoxycholic acid (NCX-1000), was found to effectively counteract the endogenous vasoconstrictors acting on the hepatic vascular tone. ${ }^{117}$

Recently use of antiangiogenic agents has been shown to reduce the collateral circulation and splachnic vasodilatation in portal vein ligated rat models. Studies in humans are awaited with interest. ${ }^{118}$

Finally, the increasing evidence of the role of bacterial infection in the pathogenesis of acute variceal bleeding makes the use of long term antibiotics (preferably nonabsorbable, such as rifaximin) a very attractive potential approach for secondary prevention which could be, and should be, tested in randomised clinical trials. ${ }^{16}$

\section{ACKNOWLEDGEMENT}

Dr Dimitrios N Samonakis is in receipt of a scholarship from the Hellenic Gastroenterology Society, 2003.

\section{Authors' affiliations}

D N Samonakis, C K Triantos, U Thalheimer, D W Patch, A K Burroughs, Liver Transplant and Hepatobiliary Medicine Unit, Royal Free Hospital, London, UK

\section{REFERENCES}

1 Garcia-Tsao G, Groszmann RJ, Fisher RL, et al. Portal pressure, presence of gastroesophageal varices and variceal bleeding. Hepatology 1985;5:419-24.

2 D'Amico G, Pagliaro L, Bosch J. The treatment of portal hypertension: a metaanalytic review. Hepatology 1995;22:332-54.

3 Grace ND. Diagnosis and treatment of gastrointestinal bleeding secondary to portal hypertension. American College of Gastroenterology Practice Parameters Committee. Am J Gastroenterol 1997;92:1081-91.

4 Prediction of the first variceal hemorrhage in patients with cirrhosis of the liver and esophageal varices. A prospective multicenter study. The North Italian Endoscopic Club for the Study and Treatment of Esophageal Varices. N Engl J Med 1988;319:983-9.

5 Cales P, Desmorat H, Vinel JP, et al. Incidence of large oesophageal varices in patients with cirrhosis: application to prophylaxis of first bleeding. Gut 1990;31:1298-302.

6 Vorobioff J, Groszmann RJ, Picabea E, et al. Prognostic value of hepatic venous pressure gradient measurements in alcoholic cirrhosis: a 10-year prospective study. Gastroenterology 1996;111:701-9.

7 Nevens F, Bustami R, Scheys I, et al. Variceal pressure is a factor predicting the risk of a first variceal bleeding: a prospective cohort study in cirrhotic patients. Hepatology 1998;27:15-19.

8 Ben Ari Z, Cardin F, McCormick AP, et al. A predictive model for failure to control bleeding during acute variceal haemorrhage. J Hepatol 1999;31:443-50.

9 Moitinho E, Escorsell A, Bandi JC, et al. Prognostic value of early measurements of portal pressure in acute variceal bleeding. Gastroenterology 1999;117:626-31
10 Goulis J, Armonis A, Patch D, et al. Bacterial infection is independently associated with failure to control bleeding in cirrhotic patients with gastrointestinal hemorrhage. Hepatology 1998;27:1207-12.

11 D'Amico G, De Franchis R. Upper digestive bleeding in cirrhosis. Posttherapeutic outcome and prognostic indicators. Hepatology 2003;38:599-612.

12 Kleber G, Sauerbruch T, Ansari H, et al. Prediction of variceal hemorrhage in cirrhosis: a prospective follow-up study. Gastroenterology 1991;10015 pt 1):1332-7.

13 McCormick PA, O'Keefe C. Improving prognosis following a first variceal haemorrhage over four decades. Gut 2001;49:682-5.

14 Bernard B, Cadranel JF, Valla D, et al. Prognostic significance of bacterial infection in bleeding cirrhotic patients: a prospective study. Gastroenterology 1995; 108:1828-34.

15 Blaise M, Pateron D, Trinchet JC, et al. Systemic antibiotic therapy prevents bacterial infection in cirrhotic patients with gastrointestinal hemorrhage. Hepatology 1994;20(1 pt 1):34-8.

16 Goulis J, Patch D, Burroughs AK. Bacterial infection in the pathogenesis of variceal bleeding. Lancet 1999;353:139-42.

17 Thuluvath PJ, Yoo HY. Portal hypertensive gastropathy. Am J Gastroenterol 2002;97:2973-8.

18 Primignani M, Carpinelli L, Preatoni P, et al. Natural history of portal hypertensive gastropathy in patients with liver cirrhosis. The New Italian Endoscopic Club for the study and treatment of esophageal varices (NIEC). Gastroenterology 2000;119:181-7.

19 Bosch J, Abraldes JG, Groszmann R. Current management of portal hypertension. J Hepatol 2003;38(suppl 1):S54-68.

20 Kouroumalis EA, Koutroubakis IE, Manousos ON. Somatostatin for acute severe bleeding from portal hypertensive gastropathy. Eur J Gastroenterol Hepatol 1998;10:509-52.

21 Pique JM. Portal hypertensive gastropathy. Baillieres Clin Gastroenterol 1997; 11:257-70.

22 Laine L, Burroughs AK, Silvain C, et al. Treatment of the acute bleeding episode. In: De Franchis R, ed. Portal hypertension III. Proceedings of the third Baveno International Consensus Workshop on Definitions, Methodology and Therapeutic Strategies. Oxford: Blackwell Science, 2001:134-69.

23 Castaneda B, Debernardi-Venon W, Bandi JC, et al. The role of portal pressure in the severity of bleeding in portal hypertensive rats. Hepatology 2000;31:581-6.

24 Soares-Weiser K, Brezis M, Tur-Kaspa R, et al. Antibiotic prophylaxis of bacterial infections in cirrhotic inpatients: a meta-analysis of randomized controlled trials. Scand J Gastroenterol 2003;38:193-200.

25 Ortega R, Gines P, Uriz J, et al. Terlipressin therapy with and without albumin for patients with hepatorenal syndrome: results of a prospective, nonrandomized study. Hepatology 2002;36(4 pt 1):941-8.

26 loannou G, Doust J, Rockey DC. Terlipressin for acute esophageal variceal hemorrhage. Cochrane Database Syst Rev 2003;(1):CD002147.

27 Goulis J, Burroughs AK. Portal hypertensive bleeding. In: McDonald J, Burroughs AK, Feagan B, eds. Evidence based gastroenterology and hepatology. BMJ Books (in press).

28 Levacher S, Letoumelin P, Pateron D, et al. Early administration of terlipressin plus glyceryl trinitrate to control active upper gastrointestinal bleeding in cirrhotic patients. Lancet 1995;346:865-8.

29 Gotzsche PC. Somatostatin analogues for acute bleeding oesophageal varices. Cochrane Database Syst Rev 2002;(1):CD000193.

30 Ejlersen E, Melsen T, Ingerslev J, et al. Recombinant activated factor VII ( $\mathrm{rFVlla}$ ) acutely normalizes prothrombin time in patients with cirrhosis during bleeding from oesophageal varices. Scand J Gastroenterol 2001;36:1081-5.

31 Thabut D, De Franchis R, Bernard B, et al. Efficacy of activated recombinant factor VII ( $r F V l l a)$ Novosen (R) in cirrhotic patients with upper gastrointestinal bleeding: a randomised placebo controlled double blind multicenter trial. $J$ Hepatol 2003;38:128A.

32 Hartigan PM, Gebhard RL, Gregory PB. Sclerotherapy for actively bleeding esophageal varices in male alcoholics with cirrhosis. Veterans Affairs Cooperative Variceal Sclerotherapy Group. Gastrointest Endosc 1997;46:1-7.

33 Seewald S, Mendoza G, Seitz U, et al. Variceal bleeding and portal hypertension: has there been any progress in the last 12 months? Endoscopy 2003;35:136-44.

34 Gross M, Schiemann U, Muhlhofer A, et al. Meta-analysis: efficacy of therapeutic regimens in ongoing variceal bleeding. Endoscopy 2001;33:737-46.

35 D'Amico G, Pietrosi G, Tarantino I, et al. Emergency sclerotherapy versus vasoactive drugs for variceal bleeding in cirrhosis: a Cochrane metaanalysis. Gastroenterology 2003;124:1277-91.

36 El-Jackie A, Rowaisha I, Waked I, et al. Octreotide vs sclerotherapy in the control of acute variceal bleeding in schistosomal portal hypertension: a randomised trial. Hepatology 1998;28:533.

37 Jenkins SA, Shields R, Davies $M$, et al. A multicentre randomised trial comparing octreotide and injection sclerotherapy in the management and outcome of acute variceal haemorrhage. Gut 1997:41:526-33.

38 Banares R, Albillos A, Rincon D, et al. Endoscopic treatment versus endoscopic plus pharmacologic treatment for acute variceal bleeding: a meta-analysis. Hepatology 2002;35:609-15.

39 Burroughs AK, Hamilton G, Phillips A, et al. A comparison of sclerotherapy with staple transection of the esophagus for the emergency control of bleeding from esophageal varices. N Engl J Med 1989;321:857-62.

40 Vangeli M, Patch D, Burroughs AK. Salvage tips for uncontrolled variceal bleeding. J Hepatol 2002;37:703-4. 
41 McCormick PA, Dick R, Panagou EB, et al. Emergency transjugular intrahepatic portasystemic stent shunting as salvage treatment for uncontrolled variceal bleeding. Br J Surg 1994;81:1324-7.

42 Sanyal AJ, Freedman AM, Luketic VA, et al. Transjugular intrahepatic portosystemic shunts for patients with active variceal hemorrhage unresponsive to sclerotherapy. Gastroenterology 1996;111:138-46.

43 Gerbes AL, Gulberg V, Waggershauser T, et al. Transjugular intrahepatic portosystemic shunt (TIPS) for variceal bleeding in portal hypertension: comparison of emergency and elective interventions. Dig Dis Sci 1998;43:2463-9.

44 Chau TN, Patch D, Chan YW, et al. "Salvage" transjugular intrahepatic portosystemic shunts: gastric fundal compared with esophageal variceal bleeding. Gastroenterology 1998;1 14:981-7.

45 Azoulay D, Castaing D, Majno P, et al. Salvage transjugular intrahepatic portosystemic shunt for uncontrolled variceal bleeding in patients with decompensated cirrhosis. J Hepatol 2001;35:590-7.

46 Patch D, Nikolopoulou V, McCormick A, et al. Factors related to early mortality after transjugular intrahepatic portosystemic shunt for failed endoscopic therapy in acute variceal bleeding. J Hepatol 1998;28:454-60.

47 Burroughs AK, Patch D. Transjugular intrahepatic portosystemic shunt. Semin Liver Dis 1999; 19:457-73.

48 Sarin SK, Lahoti D, Saxena SP, et al. Prevalence, classification and natural history of gastric varices: a long-term follow-up study in 568 portal hypertension patients. Hepatology 1992;16:1343-9.

49 Ramond MJ, Valla D, Mosnier JF, et al. Successful endoscopic obturation of gastric varices with butyl cyanoacrylate. Hepatology 1989;10:488-93.

50 Oho K, Iwao T, Sumino $M$, et al. Ethanolamine oleate versus butyl cyanoacrylate for bleeding gastric varices: a nonrandomized study. Endoscopy 1995;27:349-54.

51 Sarin SK, Jain AK, Jain M, et al. A randomized controlled trial of cyanoacrylate versus alcohol injection in patients with isolated fundic varices. Am J Gastroenterol 2002;97:1010-15

52 Williams SG, Peters RA, Westaby D. Thrombin - an effective treatment for gastric variceal haemorrhage. Gut 1994;35:1287-9.

53 Datta D, Vlavianos $P$, Alisa $A$, et al. Use of fibrin glue (beriplast) in the management of bleeding gastric varices. Endoscopy 2003;35:675-8.

54 Barange K, Peron JM, Imani K, et al. Transjugular intrahepatic portosystemic shunt in the treatment of refractory bleeding from ruptured gastric varices. Hepatology 1999;30:1139-43.

55 Tripathi D, Therapondos G, Jackson E, et al. The role of the transjugular intrahepatic portosystemic stent shunt (TIPSS) in the management of bleeding gastric varices: clinical and haemodynamic correlations. Gut 2002;51:270-4

56 Grace ND, Groszmann RJ, Garcia-Tsao G, et al. Portal hypertension and variceal bleeding: an AASLD single topic symposium. Hepatology 1998:28:868-80.

57 Agrawall SR, Gupta R, Marthy NS, et al. Comparable efficacy of propranololplus isosorbite mononitrateand endoscopic varicealligation in prevention of variceal rebleed. J Hepatol 2002;36:631A.

58 Lo GH, Chen WC, Chen MH, et al. Banding ligation versus nadolol and isosorbide mononitrate for the prevention of esophageal variceal rebleeding. Gastroenterology 2002;123:728-34.

59 Patch D, Sabin CA, Goulis J, et al. A randomized, controlled trial of medical therapy versus endoscopic ligation for the prevention of variceal rebleeding in patients with cirrhosis. Gastroenterology 2002;123:1013-19.

60 Villanueva C, Minana J, Ortiz J, et al. Endoscopic ligation compared with combined treatment with nadolol and isosorbide mononitrate to prevent recurrent variceal bleeding. N Engl J Med 2001;345:647-55.

61 Evrard S, Dumonceau JM, Delhaye M, et al. Endoscopic histoacryl obliteration vs. propranolol in the prevention of esophagogastric variceal rebleeding: a randomized trial, Endoscopy 2003;35:729-35.

62 Gournay J, Masliah C, Martin T, et al. Isosorbide mononitrate and propranolol compared with propranolol alone for the prevention of variceal rebleeding. Hepatology 2000;31:1239-45.

63 Patti R, D'Amico G, Pasta H, et al. Isosorbite mononitrate with nadolol compared to nadolol alone for prevention of recurrent bleeding in cirrhosis Double blind placebo controlled randomised trial. J Hepatol 1999;30:81.

64 Burroughs AK, Vangeli M. Transjugular intrahepatic portosystemic shunt versus endoscopic therapy: randomized trials for secondary prophylaxis of variceal bleeding: an updated meta-analysis. Scand J Gastroenterol 2002;37:249-52.

65 Escorsell A, Banares R, Garcia-Pagan JC, et al. TIPS versus drug therapy in preventing variceal rebleeding in advanced cirrhosis: a randomized controlled trial. Hepatology 2002;35:385-92.

66 Bureau C, Garcia-Pagan JC, Otal P, et al. Improved clinical outcome using polytetrafluoroethylene-coated stents for tips: results of a randomized study. Gastroenterology 2004; 126:469-75.

67 Sarfeh IJ, Rypins EB. Partial versus total portacaval shunt in alcoholic cirrhosis. Results of a prospective, randomized clinical trial. Ann Surg 1994;219:353-61

68 Collins JC, Ong MJ, Rypins EB, et al. Partial portacaval shunt for variceal hemorrhage: longitudinal analysis of effectiveness. Arch Surg 1998;133:590-2.

69 Merkel C, Bolognesi M, Sacerdoti D, et al. The hemodynamic response to medical treatment of portal hypertension as a predictor of clinical effectiveness in the primary prophylaxis of variceal bleeding in cirrhosis. Hepatology 2000:32:930-4.

70 Tarantino I, Abraldes JG, Turnes J, et al. The HVPG-responseto pharmacological treatmentof portal hypertension predictsprognosis and the risk of developing complications of cirrhosis. J Hepatol 2002;36/suppl 1): 15A.
71 Thalheimer U, Mela M, Patch D, et al. Monitoring target reduction in hepatic venous pressure gradient during pharmacological therapy of portal hypertension: a close look at the evidence. Gut 2004;53:143-8.

72 de Franchis R. Updating consensus in portal hypertension: report of the Baveno III Consensus Workshop on definitions, methodology and therapeutic strategies in portal hypertension. J Hepatol 2000;33:846-52.

73 D'Amico G, Pagliaro L, Bosch J. Pharmacological treatment of portal hypertension: an evidence-based approach. Semin Liver Dis 1999; 19:475-505

74 Poynard T, Cales P, Pasta L, et al. Beta-adrenergic-antagonist drugs in the prevention of gastrointestinal bleeding in patients with cirrhosis and esophageal varices. An analysis of data and prognostic factors in 589 patients from four randomized clinical trials. Franco-Italian Multicenter Study Group. N Engl J Med 1991;324:1532-8.

75 Abraczinskas DR, Ookubo R, Grace ND, et al. Propranolol for the prevention of first esophageal variceal hemorrhage: a lifetime commitment? Hepatology 2001;34:1096-102.

76 Garcia-Pagan JC, Villanueva C, Vila MC, et al. Isosorbide mononitrate in the prevention of first variceal bleed in patients who cannot receive betablockers. Gastroenterology 2001;121:908-14.

77 Garcia-Pagan JC, Feu F, Navasa M, et al. Long-term haemodynamic effects of isosorbide 5-mononitrate in patients with cirrhosis and portal hypertension. J Hepatol 1990;11:189-95.

78 Angelico M, Carli L, Piat C, et al. Effects of isosorbide-5-mononitrate compared with propranolol on first bleeding and long-term survival in cirrhosis. Gastroenterology 1997; 113:1632-9.

79 Garcia-Pagan JC, Morillas R, Banares R, et al. Propranolol plus placebo versus propranolol plus isosorbide-5-mononitrate in the prevention of a first variceal bleed: a double-blind RCT. Hepatology 2003;37:1260-6.

80 Merkel C, Marin R, Enzo E, et al. Randomised trial of nadolol alone or with isosorbide mononitrate for primary prophylaxis of variceal bleeding in cirrhosis. Gruppo-Triveneto per L'ipertensione Portale (GTIP). Lancet 1996:348:1677-81.

81 Merkel C, Marin R, Sacerdoti D, et al. Long-term results of a clinical trial of nadolol with or without isosorbide mononitrate for primary prophylaxis of variceal bleeding in cirrhosis. Hepatology 2000;31:324-9.

82 Sarin SK, Lamba GS, Kumar M, et al. Comparison of endoscopic ligation and propranolol for the primary prevention of variceal bleeding. NEngl J Med 1999;340:988-93.

83 De BK, Ghoshal UC, Das T, et al. Endoscopic variceal ligation for primary prophylaxis of oesophageal variceal bleed: preliminary report of a randomized controlled trial. J Gastroenterol Hepatol 1999:14:220-4.

84 Lui HF, Stanley AJ, Forrest EH, et al. Primary prophylaxis of variceal hemorrhage: a randomized controlled trial comparing band ligation, propranolol, and isosorbide mononitrate. Gastroenterology 2002;123:735-44.

85 Triantos C, Vlachogiannakos J, Armonis A, et al. Is prophylactic banding always safe ? Randomized controlled trial for the prevention of the first variceal bleeding in cirrhotic patients with contraindications or intolerance to B-Blockers. J Hepatol 2004;40(suppl No 1):73-74.

86 Fleig WE. To scope or not to scope: still a question. Hepatology 2001;33:471-2

87 Schepis F, Camma C, Niceforo D, et al. Which patients with cirrhosis should undergo endoscopic screening for esophageal varices detection? Hepatology 2001;33:333-8.

88 Pilette C, Oberti F, Aube C, et al. Non-invasive diagnosis of esophageal varices in chronic liver diseases. J Hepatol 1999;31:867-73.

89 Ong J. Clinical predictors of large esophageal varices: how accurate are they? Am J Gastroenterol 1999;94:3103-5.

90 de Franchis R. Evaluation and follow-up of patients with cirrhosis and oesophageal varices. J Hepatol 2003;38:361-3.

91 Merli M, Nicolini G, Angeloni S, et al. Incidence and natural history of small esophageal varices in cirrhotic patients. J Hepatol 2003;38:266-72.

92 Lin HC, Soubrane O, Cailmail S, et al. Early chronic administration of propranolol reduces the severity of portal hypertension and portal-systemic shunts in conscious portal vein stenosed rats. J Hepatol 1991;13:213-19.

93 Sarin SK, Groszmann RJ, Mosca PG, et al. Propranolol ameliorates the development of portal-systemic shunting in a chronic murine schistosomiasis model of portal hypertension. J Clin Invest 1991;87:1032-6.

94 Cales P, Oberti F, Payen JL, et al. Lack of effect of propranolol in the prevention of large oesophageal varices in patients with cirrhosis: a randomized trial. French-Speaking Club for the Study of Portal Hypertension. Eur J Gastroenterol Hepatol 1999;11:741-5

95 Escorsell A, Ferayorni L, Bosch J, et al. The portal pressure response to betablockade is greater in cirrhotic patients without varices than in those with varices. Gastroenterology 1997;112:2012-16.

96 Groszmann R, Garcia-Tsao G, Makuch RW, et al. Multicentre randomised placebo-controlled trial of non-selective beta blockers in the prevention of the complications of portal hypertension: final results and identification of a predictive factor. Hepatology 2003;38(4 S1).

97 Merkel C, Marin R, Angeli P, et al. Beta-blockers in the prevention of aggravation of oesophageal varices in patients with cirrhosis and small varices: a placebo controlled clinical trial. Hepatology 2003;38(4 S1).

98 Frishman WH. Carvedilol. N Engl J Med 1998;339:1759-65.

99 Hemstreet BA. Evaluation of carvedilol for the treatment of portal hypertension. Pharmacotherapy 2004;24:94-104

100 Cereda JM, Roulot D, Braillon A, et al. Reduction of portal pressure by acute administration of furosemide in patients with alcoholic cirrhosis. J Hepatol 1989;9:246-51.

101 Okumura H, Aramaki T, Katsuta Y, et al. Reduction in hepatic venous pressure gradient as a consequence of volume contraction due to chronic 
administration of spironolactone in patients with cirrhosis and no ascites. Am J Gastroenterol 1991;86:46-52.

102 Nevens F, Lijnen P, VanBilloen $\mathrm{H}$, et al. The effect of long-term treatment with spironolactone on variceal pressure in patients with portal hypertension without ascites. Hepatology 1996;23:1047-52.

103 Sen S, De Binay K, Biswas PK, et al. Hemodynamic effect of spironolactone in liver cirrhosis and propranolol-resistant portal hypertension. Indian J Gastroenterol 2002;21:145-8.

104 Sugano S, Suzuki T, Nishio M, et al. Chronic splanchnic hemodynamic effects of low-dose transdermal nitroglycerin versus low-dose transdermal nitroglycerin plus spironolactone in patients with cirrhosis. Dig Dis Sci 1997:42:529-35.

105 Abecasis R, Kravetz D, Fassio E, et al. Nadolol plus spironolactone in the prophylaxis of first variceal bleed in nonascitic cirrhotic patients: a preliminary study. Hepatology 2003;37:359-65.

106 Bataller R, Gines P, Nicolas JM, et al. Angiotensin II induces contraction and proliferation of human hepatic stellate cells. Gastroenterology 2000;118:1149-56.

107 Schepke M, Werner E, Biecker E, et al. Hemodynamic effects of the angiotensin II receptor antagonist irbesartan in patients with cirrhosis and portal hypertension. Gastroenterology 2001;121:389-95.

108 Venon WD, Baronio M, Leone N, et al. Effects of long-term Irbesartan in reducing portal pressure in cirrhotic patients: comparison with propranolol in a randomised controlled study. J Hepatol 2003;38:455-60.

109 Schneider AW, Kalk JF, Klein CP. Effect of losartan, an angiotensin II receptor antagonist, on portal pressure in cirrhosis. Hepatology 1999;29:334-9.

110 Gonzalez-Abraldes J, Albillos A, Banares R, et al. Randomized comparison of long-term losartan versus propranolol in lowering portal pressure in cirrhosis. Gastroenterology 2001;121:382-8.
111 De BK, Bandyopadhyay K, Das TK, et al. Portal pressure response to losartan compared with propranolol in patients with cirrhosis. Am J Gastroenterol 2003;98:1371-6.

112 Vlachogiannakos J, Tang AK, Patch D, et al. Angiotensin converting enzyme inhibitors and angiotensin II antagonists as therapy in chronic liver disease. Gut 2001;49:303-8.

113 Sogni P, Moreau R, Gomola A, et al. Beneficial hemodynamic effects of bosentan, a mixed $E T(A)$ and $E T(B)$ receptor antagonist, in portal hypertensive rats. Hepatology 1998;28:655-9.

114 Reynaert H, Vaeyens F, Qin H, et al. Somatostatin suppresses endothelin-1 induced rat hepatic stellate cell contraction via somatostatin receptor subtype 1. Gastroenterology 2001;121:915-30.

115 Vaughan RB, Angus PW, Chin-Dusting JP. Evidence for altered vascular responses to exogenous endothelin-1 in patients with advanced cirrhosis with restoration of the normal vasoconstrictor response following successful liver transplantation. Gut 2003;52:1505-10.

116 Wiest R, Groszmann RJ. The paradox of nitric oxide in cirrhosis and portal hypertension: too much, not enough. Hepatology 2002;35:478-91.

117 Fiorucci S, Antonelli E, Brancaleone V, et al. NCX-1000, a nitric oxidereleasing derivative of ursodeoxycholic acid, ameliorates portal hypertension and lowers norepinephrine-induced intrahepatic resistance in the isolated and perfused rat liver. J Hepatol 2003;39:932-9.

118 Fernandez M, Mejias M, Angermayr B, et al. Inhibition of VEGF receptor-2 (VEGFR-2) signaling prevents portal-systemic collateral (PSC) vessel formation in rats with portal hypertension (PH). J Hepatol 2004;40(suppl No 1).

119 Burroughs AK. General management of the cirrhotic patient with acute variceal bleeding. In: De Franchis $\mathrm{R}$, ed. Portal hypertension:proceedings of the third Baveno international consensus workshop on definitions, methodology and therapeutic strategies. Oxford: Blackwell Science, 2001:135-42.

\section{Call for papers}

10th European Forum on Quality Improvement in Health Care 13-15 April 2005, ExCel, Docklands, London For further information on how to submit your paper please go to: http://www.quality.bmipg.com 